\title{
Winter Wheat Growth Monitoring Using Multi-temporal TerraSAR-X Dual-polarimetric Data
}

\author{
Rei SONOBE ${ }^{1 *}$, Hiroshi TANI ${ }^{2}$, Xiufeng WANG, ${ }^{2}$ Nobuyuki KOBAYASHI ${ }^{3}$ and \\ Hideki SHIMAMURA ${ }^{4}$
}

${ }^{1}$ Graduate School of Agriculture, Hokkaido University (Sapporo, Hokkaido 060-8589, Japan)

${ }^{2}$ Research Faculty of Agriculture, Hokkaido University (Sapporo, Hokkaido 060-8589, Japan)

${ }^{3}$ Hokkaido Intellect Tank (Sapporo, Hokkaido 060-0004, Japan)

${ }^{4}$ PASCO Corporation (Meguro ward, Tokyo 153-0043, Japan)

\begin{abstract}
This paper describes a method for monitoring winter wheat growth using multi-temporal TerraSAR-X dual-polarimetric data. Six TerraSAR-X HH/VV images were collected in Hokkaido, and the temporal responses to the winter wheat fields were analyzed. The height, moisture content and dry matter of the crops were measured at nearly the same time as TerraSAR-X data was acquired, and the relationships between these parameters and SAR data, including sigma naught and coherence, were studied. Quadratic relationships between the crop height and sigma naught were observed for HH polarization. The determination coefficient was 0.73 and the model had an RMS error of $0.17 \mathrm{~dB}$ for the validation data. Coherence is expressed as a regression equation with two explanatory variables: crop height and elongation. Next, the determination coefficient of 0.69 was observed for HH, while the RMS error of coherence was 0.01 for the validation data. The possibility of using the co-polarization ratio of TerraSAR-X to estimate the vegetation's water content was also analyzed and a determination coefficient of 0.70 was obtained. The results confirm that X-band SAR data possess great potential for the development of an operational system for monitoring wheat growth.
\end{abstract}

Discipline: Information technology

Additional key words: coherence, sigma naught

\section{Introduction}

Wheat is one of the most important crops for a large part of the world, hence the importance of monitoring its biophysical variables for agricultural management and yield prediction. Remote sensing data are useful for estimating parameters such as crop height and water content on a regional scale, with optical remote sensing of agricultural fields widely adopted and clearly beneficial (Ju, et al. 2010, Sarker \& Nichol 2011). However, observations using optical sensors sometimes suffer from interference due to clouds or rain. Conversely, synthetic aperture radars (SAR) can be used for Earth observation, even under rainy, cloudy or dark conditions and are also more sensitive to surface characteristics, which allows more reliable and consistent monitoring of agricultural fields.

Many experimental activities have been performed to evaluate the use of multi-temporal C-band synthetic aperture radar (SAR) data to map and monitor rice growth (Chen et al. 2007, Kurusu et al. 1995). However, the sigma naught of L-bands and sometimes C-bands is related not only to vegetation but also to soil moisture and surface roughness in most agricultural fields (Sonobe \& Tani 2009, Zribi \& Dechambre 2003). The effect of vegetation canopy is the main factor for X-band data over vegetated fields, and it has been shown that the sigma naught by $\mathrm{X}$-bands is explained as a function of the crop height of rice plants (Kim et al. 2000). TerraSAR-X was launched on June 15, 2007, and X-band SAR data are widely available. The objective of the mission was to develop an operational spaceborne X-band synthetic aperture radar (SAR) system to produce various processed data for commercial and scientific use. TerraSAR-X delivers X-band SAR data at a high spatial resolution of 2.5-6 $\mathrm{m}$ in a $30 \mathrm{~km}$ swathe in the Stripmap mode. Furthermore, several studies have proven the high geometric accuracy of TerraSAR-X (Ager \& Bresnahan 2009). However, the potential use of satellite-based SAR data for vegetation characterization, plant physiological parameter estimation 


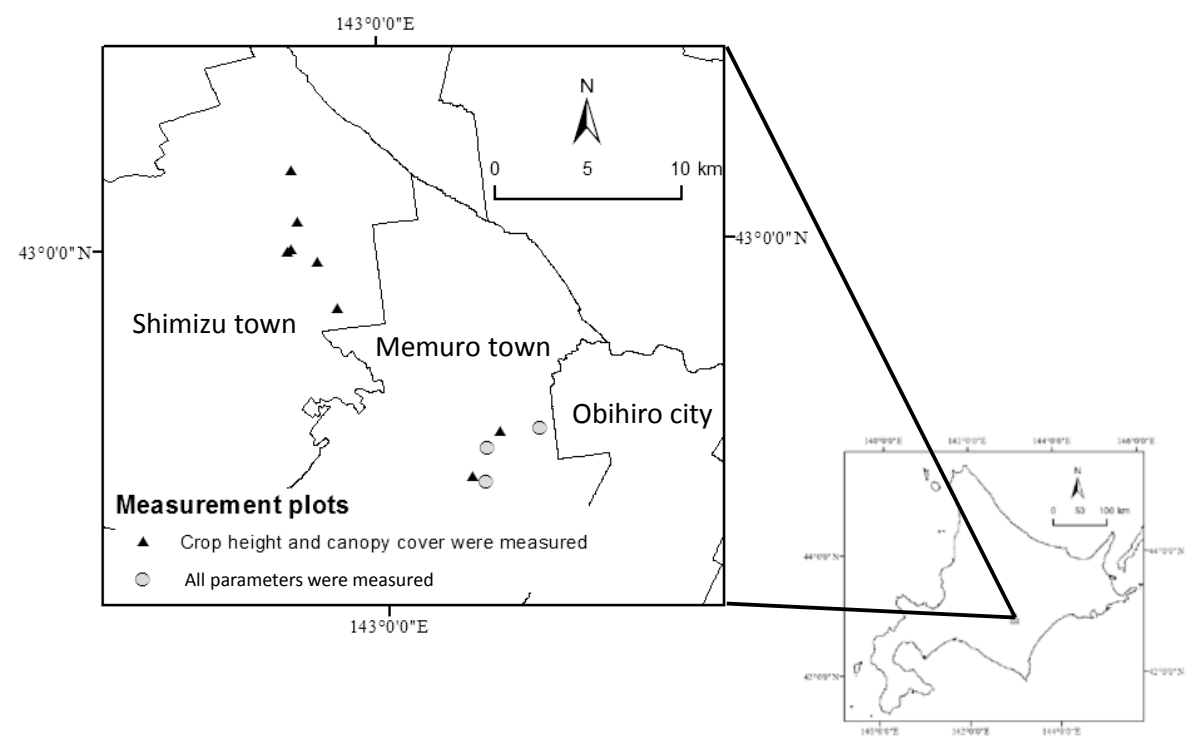

Fig. 1. The test site, located southeast of Hokkaido, Japan

Table 1. Acquisition dates and parameters of TerraSAR-X data

\begin{tabular}{|c|c|c|c|c|c|c|c|c|}
\hline Year & Mode & Date & Growth stage & Path direction & Rel. orbit & Look direction & Pol. & Incidence angle $\left(^{\circ}\right)$ \\
\hline 2013 & StripMap & $\begin{array}{c}\text { May } 15 \\
\text { May } 26 \\
\text { June } 6 \\
\text { June } 17 \\
\text { June } 28 \\
\text { July } 9\end{array}$ & $\begin{array}{l}\text { Stem elong. } \\
\text { Stem elong. } \\
\text { Booting } \\
\text { Flowering } \\
\text { Ripening } \\
\text { Ripening }\end{array}$ & Ascending & 80 & Right & $\mathrm{HH} / \mathrm{VV}$ & 42.3 \\
\hline
\end{tabular}

and yield prediction are not fully understood (Gebhardt et al. 2012). The objective of this study is to analyze the potential for monitoring winter wheat fields using multi-temporal TerraSAR-X dual-polarimetric data.

In addition, strong linear relationships between interferometric coherence on one day and the crop height of winter wheat have been established (Blaes \& Defourny 2003), as well as showing that the tandem coherence of these crops declines with increasing crop height. The TerraSAR-X repeat pass data were used in this study, although elongation over the 11 days could affect the coherence values. This study also examines the potential for monitoring winter wheat fields using coherence data.

\section{Materials and Methods}

The experimental area of this study is the farming area in the western Tokachi plain, Hokkaido, Japan (Fig. 1). TerraSAR-X data were acquired between May 15 and July 9, 2013. Details of the acquired data are presented in Table 1 , and the perpendicular baselines between interferometric SAR (InSAR) pairs are presented in Table 2. TerraSAR-X
Table 2. TerraSAR-X data sequence

\begin{tabular}{ccc}
\hline \hline Data pairs & Perpendicular baseline $(\mathrm{m})$ & Days separation \\
\hline May 15 - May 26 & 66 & 11 \\
May 26 - June 6 & -117 & 11 \\
June 6 - June 17 & -101 & 11 \\
June 17 - June 28 & 53 & 11 \\
June 28 - July 9 & 48 & 11 \\
\hline
\end{tabular}

is a side-looking $\mathrm{X}$-band synthetic aperture radar (SAR), based on active phased array antenna technology (Roth et al. 2004) and flies in a sun-synchronous dawn-dusk 11-day repeat orbit at an altitude of $514 \mathrm{~km}$ at the equator. Although the operational lifetime is 5 years, TanDEM-X, with equivalent specifications, was launched on June 21, 2010, and the launch of TerraSAR-X2 is planned in future, which will enable regular observation of these data.

In this study, Single Look Slant Range Complex (SSC) products operated in Stripmap mode were used. The TerraSAR-X data were converted into sigma naught, and coherence values were calculated. When calculating the coherence, only adjacent pairs were used because it has been indicated that the InSAR quality is low if the interval 


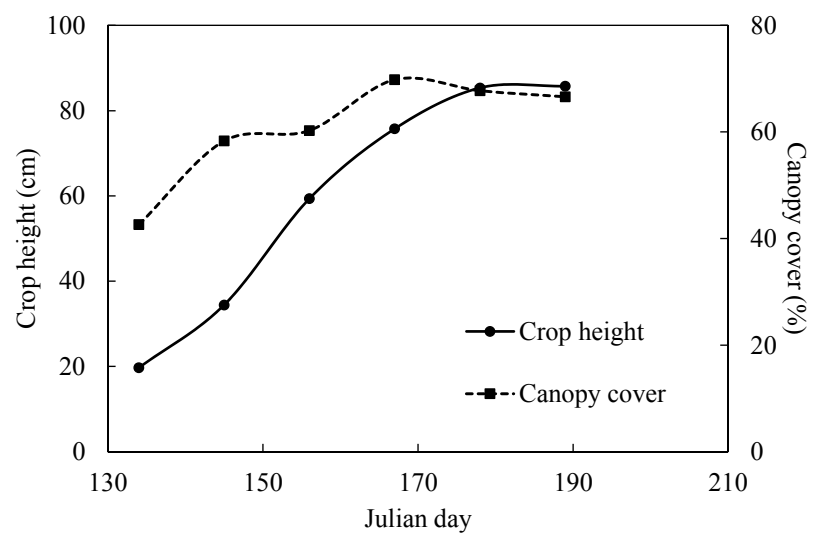

Fig. 2. The growing process of the canopy cover and height

between subsequent observations exceeds 22 days (Short et al. 2011). To compensate for spatial variability and avoid problems related to uncertainty in georeferencing, the average sigma naught $(\mathrm{dB})$ was assigned to each field.

Parallel to the TerraSAR-X observation, a ground survey measuring canopy height, soil moisture and canopy cover for the 11 winter wheat fields was conducted. Some measures are missing because of agricultural works such as crop-dusting operations. In the three fields, wet and dry weights were also measured, and vegetation water content (VWC) was calculated from June 6 to July 9.

In mid-May, sigma naught is high because of doublebounce scattering, while from late May onward, the volume scattering dominates, and sigma naught becomes low over time. However, during the growth period, diffuse reflection is the predominant response, and sigma naught increases. The relationships are described using quadratic regression equations, which were also used in this study (Kim et al. 2000). Because crop height reference data are obtained at a total of 59 points, 19 randomly selected points of reference data were left out of the modeling process for the subsequent independent validation and the coefficients used to determine $r^{2}$ for the regression models were calculated.

In some studies of biomass estimation using coherence, the tandem SAR pair was used because the change in crop height can be neglected between satellite observations, and the linear relationships between crop height and coherence were indicated using the following equation (Blaes \& Defourny 2003, Gebhardt et al. 2012):

$$
\rho=f(H)=a_{1} H+a_{2}
$$

where $\rho$ is the interferometric coherence, $\mathrm{H}$ is the crop height (in $\mathrm{cm}$ ), and $a_{1}$ and $a_{2}$ are regression coefficients.

However, satellite SAR tandem pairs are unavailable in most situations, so we estimate coherence using crop height and elongation via the following equation:

$$
\rho=f\left(H_{\text {master }}\right) \cdot g\left(H_{\text {growuh }}\right)=a_{3} H_{\text {master }}+a_{4} H_{\text {growth }}+a_{5} H_{\text {master }} \cdot H_{\text {growlh }}+a_{6}
$$

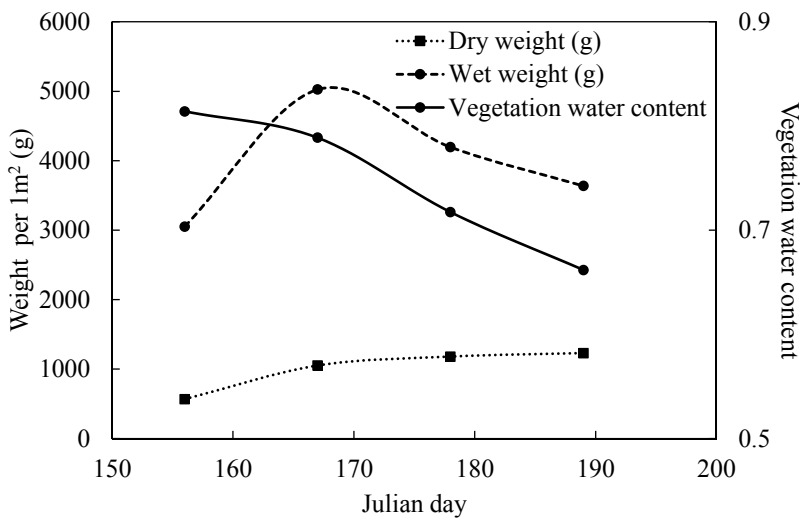

Fig. 3. The growing process of dry weight, wet weight and vegetation water content

where $H_{\text {master }}$ is the crop height (in $\mathrm{cm}$ ) on the master data acquisition date, $H_{\text {growt }}$ is the elongation (in $\mathrm{cm}$ ) during one repeat pass, and $a_{3}, a_{4}, a_{5}$ and $a_{6}$ are regression coefficients. Crop height (on the date of master data acquisition) and elongation data (over the 11 days) at a total of 35 points were obtained, and 19 randomly selected points were left out in the modeling process for the subsequent independent validation. The coefficients used to determine $r^{2}$ for the regression models were calculated.

VWC has a high correlation with NDVI. ${ }^{7}$ In addition, a high correlation was also shown between NDVI and the copolarization ratio $\left(\sigma_{H H}^{0} / \sigma_{V V}^{0}\right)$ of L-bands (Bindlish \& Barros 2001, Saradjian \& Hosseini 2011). Therefore, with the aim of analyzing the possibility of using $\sigma_{H H}^{0} / \sigma_{V V}^{0}$ of X-bands to estimate VWC, the following linear regression equation for the study area is constructed:

$$
V W C=a_{7} \sigma_{H H}^{0} / \sigma_{V V}^{0}+a_{8}
$$

where $a_{7}$ and $a_{8}$ are regression coefficients. Biomass data at a total of 12 points were obtained and all the data were used to establish a robust model.

\section{Results and Discussion}

The temporal evolution of the crop canopy cover and the crop height of winter wheat measured during the 2013 growth period is shown in Fig. 2. The relationship between biomass and the Julian day and that between vegetation water content (VWC) and the Julian day are presented in Fig. 3. The growth of winter wheat was observed until June 28.

The total backscattering strength from the crop is regarded as a function of direct backscattering strength from the ground, the stem-ground backscattering strength, the direct backscattering strength from the stem, the canopyground backscattering strength and the canopy backscattering strength; including multiple scattering within the canopy. As for ground interaction, factors such as soil surface roughness and soil moisture are important elements. The magni- 
tude of each of these backscatter components depends upon the radar wavelength, polarization, the angle of incidence and the canopy parameters.

The relationship between the sigma naught of TerraSAR-X data and crop height can be established on the grounds of the data set illustrated in Fig. 4. The following equations are constructed:

$$
\begin{aligned}
& \sigma_{H H}^{0}=0.000739 H^{2}-0.111 H-9.74 \\
& \sigma_{V V}^{0}=0.000483 H^{2}-0.665 H-11.45
\end{aligned}
$$

where $\sigma_{H H}^{0}$ and $\sigma_{V V}^{0}$ represent sigma naught (in $\mathrm{dB}$ ) for $\mathrm{HH}$ and $\mathrm{VV}$ polarization, respectively. $\mathrm{H}$ can be estimated by solving the equations. However, the ranges of these models are limited. The maximum crop height is $75.1 \mathrm{~cm}$ for $\mathrm{HH}$ and $68.8 \mathrm{~cm}$ for VV polarizations of the vertices of the quadratic regression equations. The applicable limit for $\mathrm{HH}$ polarization was nearly equal to the height on June 17 $(75.7 \mathrm{~cm})$ and the limit for VV polarization was between the height on June $6(59.3 \mathrm{~cm})$ and that on June 17. Determination coefficients of 0.73 and 0.31 were observed for $\mathrm{HH}$ and $\mathrm{VV}$ and the results show that sigma naught is available for crop height estimations until mid-June.

Using these models and the reference data, we obtained the estimated sigma naught values, which are compared with measured values. Although the reference data include data for crop heights that exceed the limitations described above, regression models can be applied to express the backscattering strength using crop height values that exceed the limitations. The Root Mean Square (RMS) errors were 0.17 and $0.42 \mathrm{~dB}$ for the validation data. To estimate a crop height using the inversion of eq. (4) or (5), the lower value should be chosen.

The regression equations used to estimate coherence via crop height and elongation are as follows:

$$
\begin{array}{r}
\rho_{H H}=-3.05 \mathrm{E}-04 H_{\text {master }}-1.29 \mathrm{E}-03 H_{\text {growh }}+1.52 \mathrm{E}-05 H_{\text {master }} H_{\text {growwh }}+0.43 \\
\rho_{V V}=-1.62 \mathrm{E}-05 H_{\text {master }}+2.83 \mathrm{E}-04 H_{\text {growh }}-3.69 \mathrm{E}-06 H_{\text {master }} H_{\text {growht }}+0.40
\end{array}
$$

where $\rho_{\mathrm{HH}}$ and $\rho_{\mathrm{VV}}$ represent the interferometric coherence for $\mathrm{HH}$ and VV polarization, respectively. Although the determination coefficients of 0.69 and 0.39 were observed for $\mathrm{HH}$ and $\mathrm{VV}$, respectively, the model for VV polarization was insignificant at the $10 \%$ significance level, and we assessed that the model for VV polarization was unusable. Although the Root Mean Square (RMS) error of coherence was 0.01 for the validation data, either crop height or elongation had to be given to estimate crop parameter, whereupon the following equations were obtained to estimate $H_{\text {growth }}$ using $\rho_{\mathrm{HH}}$ and $H_{\text {master }}$ by inversion equation (6):

$$
H_{\text {growth }}=\frac{\rho_{H H}+3.05 \mathrm{E}-04 H_{\text {master }}-0.43}{1.52 \mathrm{E}-05 H_{\text {master }}-1.29 \mathrm{E}-03}
$$

The RMS error was $7.0 \mathrm{~cm}$, and the mean relative error

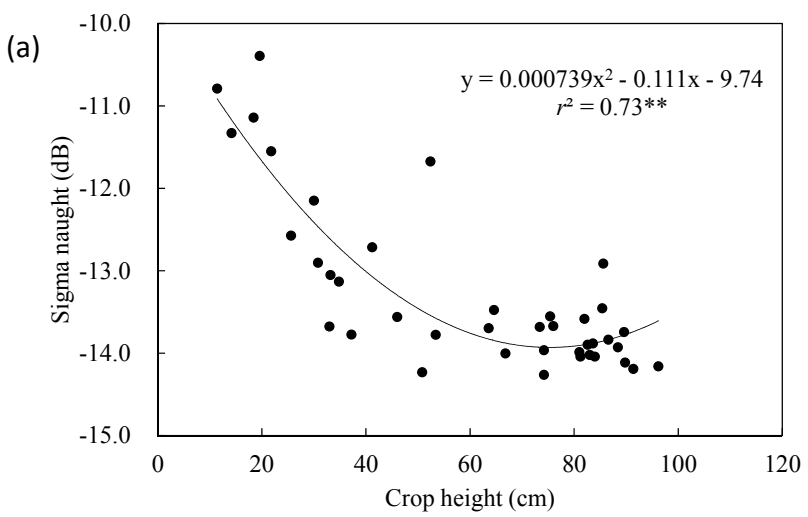

(b)

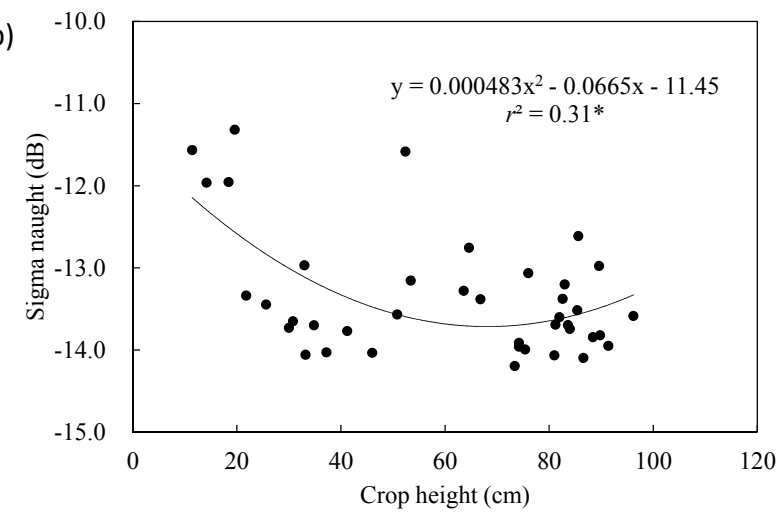

Fig. 4. The relationship between crop height and sigma naught of HH (a) and the relationship between crop height and sigma naught of $\mathrm{VV}$ polarization (b)

was equal to $-31.2 \%$. The baseline length also varied between the two interferometric pairs. The baseline length of the days between May 26 and June 6 was approximately twice that of the days between June 17 and 28 (Table 2). The coherence also declined with increasing baseline length (Zebker \& Villasenor 1992). However, higher coherence values were not observed for the days between June 17 and 28 compared to those between May 26 and June 6. It is not possible to infer a conclusion from this, but the influence of the crop height in this study exceeds that of baseline length. This also appears to be a major advantage of InSAR coherence data for crop parameter retrieval and crop monitoring over a growing season. The above results show that a combination of sigma naught and coherence will offer a clearer crop monitoring solution and solve the limitation of applied growth stages related to the problem of estimating two crop height values with sigma naught.

Fig. 5 represents the relationships between biomass parameters (wet weight and dry weight) and sigma naught for $\mathrm{HH}$ and $\mathrm{VV}$ polarization or the co-polarization ratio $\left(\sigma_{H H}^{0} / \sigma_{V V}^{0}\right)$. For biomass parameters and sigma naught, the determination coefficients ranged between 0.020 (wet weight and $\mathrm{HH}$ polarization, $p=0.662$ ) and 0.036 (wet weight and $\mathrm{VV}$ polarization, $p=0.552$ ). Using the co-polarization ratio, the linear regression was obtained for dry weight $\left(r^{2}=0.39\right.$, 
(a)

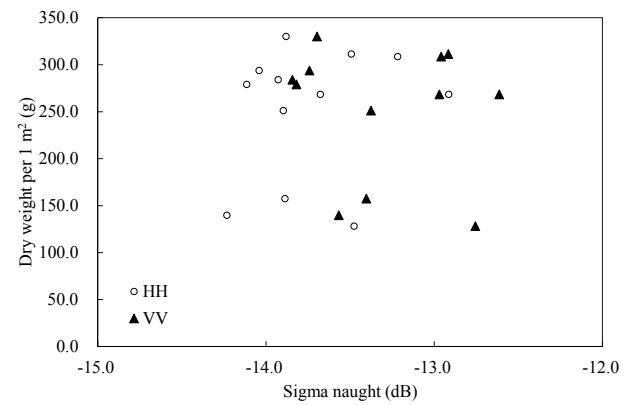

(b)

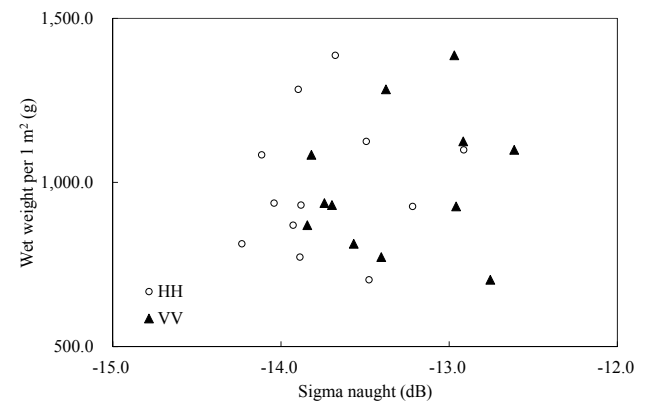

(c)

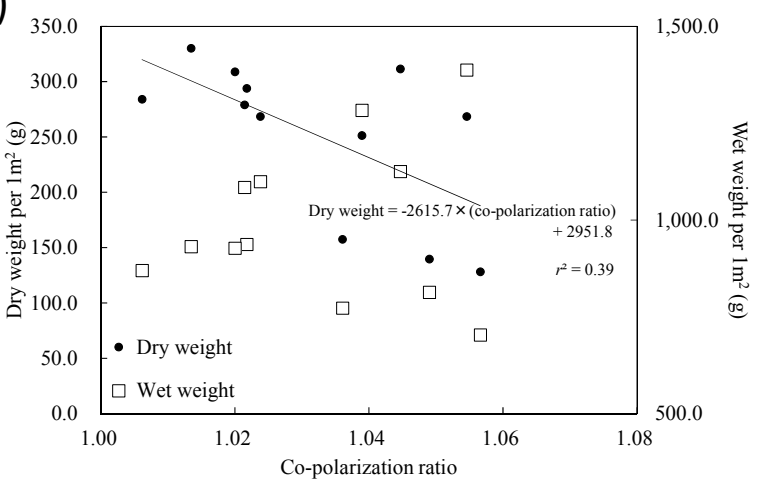

Fig. 5. The relationship between dry weight and sigma naught, the relationship between wet weight and sigma naught (b) and the relationship between copolarization ratio and two biomass parameters (c)

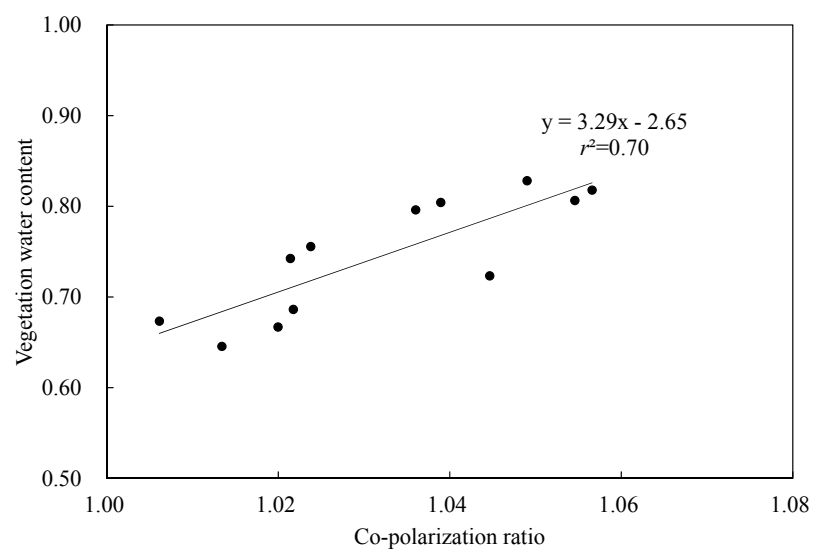

Fig. 6. The relationship between the co-polarization ratio and vegetation water content $p=0.030$ ), although the correlative relationship was not confirmed for wet weight $\left(r^{2}=0.020, p=0.659\right)$. Furthermore, we analyzed the possibility of using the co-polarization ratio to estimate VWC and the following linear regression analysis (Fig. 6) was performed for the study area. As seen in the figure, there is a linear relationship between VWC and copolarization ratio of TerraSAR-X as follows:

$$
V W C=3.29 \sigma_{H H}^{0} / \sigma_{V V}^{0}-2.65
$$

A determination coefficient of 0.70 was a;sp observed, although the relationships between sigma naught values and VWC were unclear $\left(r^{2}=0.01\right.$ and 0.11 for $\mathrm{HH}$ and VV respectively).

\section{Conclusions}

This study demonstrated that TerraSAR-X HH and VV polarization data operated in Stripmap mode exhibit considerable potential for agricultural applications. Six acquisitions and the corresponding 11-day interval coherence values were analyzed together with in-situ measurements.

First, the high sensitivity of the sigma naught to the crop height was demonstrated statistically and the quadratic relationships between crop height and sigma naught were observed with determination coefficients of 0.73 and 0.31 and RMS errors of 0.17 and $0.42 \mathrm{~dB}$ for $\mathrm{HH}$ and VV polarization respectively. However, the models could be used when the crop height was less than 75.1 and $68.8 \mathrm{~cm}$ for $\mathrm{HH}$ and VV polarization respectively.

Secondly, we estimated coherence using the crop height and elongation. Although determination coefficients of 0.69 and 0.39 were observed for $\mathrm{HH}$ and $\mathrm{VV}$, respectively, the model for VV polarization was insignificant and the RMS error of coherence was 0.01 for the validation data, which meant a combination of sigma naught and coherence would offer a clearer crop monitoring solution and solve the problem of estimating two crop height values with sigma naught. Unfortunately, agricultural monitoring applications of the tandem SAR mission are currently restricted by the availability of appropriate data. The great sensitivity of the coherence to the crop parameters should be studied in future by making TerraSAR-X/TanDEM-X tandem pairs available to the public.

Finally, the possibility of using the co-polarization ratio $\sigma_{H H}^{0} / \sigma_{V V}^{0}$ of TerraSAR-X to estimate VWC was evaluated and a determination coefficient of 0.70 was observed.

\section{Acknowledgements}

For the in-situ survey and analysis, we received considerable help from Messrs. Yasuhito Kojima and Yusuke Araki of Hokkaido University. We also thank the reviewers for their constructive comments, which have helped to improve the manuscript. 


\section{References}

Ager, T. P. \& Bresnahan, P. C. (2009) Geometric precision in space radar imaging: results from TerraSAR-X. Proc. ASPRS 2009 Annu. Conf., 9-13.

Bindlish, R. \& Barros, A. P. (2001) Parameterization of vegetation backscatter in radar-based, soil moisture estimation. Remote Sens. Environ., 76, 130-137.

Blaes, X. \& Defourny, P. (2003) Retrieving crop parameters based on tandem ERS 1/2 interferometric coherence images. Remote Sens. Environ., 88, 374-385.

Chen, J. et al. (2007) Application of ENVISAT ASAR data in mapping rice crop growth in southern China. IEEE Geosci. Remote Sens. Lett., 4, 431-435.

Engdahl, M. E. et al. (2001) The use of ERS-1/2 tandem interferometric coherence in the estimation of agricultural crop heights. IEEE Trans. Geosci. Remote Sens., 39, 1799-1806.

Gebhardt, S. et al. (2012) A comparison of TerraSAR-X Quadpol backscattering with RapidEye multispectral vegetation indices over rice fields in the Mekong Delta, Vietnam. Int. J. Remote Sens., 33, 7644-7661.

Jackson, T. J. et al. (2004) Vegetation water content mapping using Landsat data derived normalized difference water index for corn and soybeans. Remote Sens. Environ., 92, 475-482.

$\mathrm{Ju}, \mathrm{W}$. et al. (2010) Combining an ecological model with remote sensing and GIS techniques to monitor soil water content of croplands with a monsoon climate. Agric. Water Manage., 97, 1221-1231.
Kim, S. B. et al. (2000) Radar backscattering measurements of rice crop using X-band scatterometer. IEEE Trans. Geosci. Remote Sens., 38, 1467-1471.

Kurusu, T. et al. (1995) Monitoring of rice crop growth from space using the ERS-1 C-band SAR. IEEE Trans. Geosci. Remote Sens., 33, 1092-1096.

Roth, A. et al. (2004) Geocoding of TerraSAR-X data, Proc. Int. 20th ISPRS Congr., 840-844.

Saradjian, M. R. \& Hosseini, M. (2011) Soil moisture estimation by using multipolarization SAR image. Adv. Space Res., 48, 278-286.

Sarker, L. R. \& Nichol, J. E. (2011) Improved forest biomass estimates using ALOS AVNIR-2 texture indices. Remote Sens. Environ., 115, 968-977.

Short, N. et al. (2011) A comparison of TerraSAR-X, RADARSAT-2 and ALOS PALSAR interferometry for monitoring permafrost environments, case study from Herschel Island, Canada. Remote Sens. Environ., 115, 3491-3506.

Sonobe, R. \& Tani, H. (2009) Application of the Sahebi model using ALOS/PALSAR and $66.3 \mathrm{~cm}$ long surface profile data. Int. J. Remote Sens., 30, 6069-6074.

Zebker, H. A. \& Villasenor, J. (1992). Decorrelation in interferometric radar echoes. IEEE Trans. Geosci. Remote Sens., 30, 950-959.

Zribi, M. \& Dechambre, M. (2003) A new empirical model to retrieve soil moisture and roughness from C-band radar data. Remote Sens. Environ., 84, 42-52. 